\title{
Polyester and Polyesterimide Compounds with Nanofillers for Impregnating of Electrical Motors
}

\author{
B. GORNICKA ${ }^{a * *}$ AND E. PROCIOW ${ }^{b}$ \\ ${ }^{a}$ Electrotechnical Institute, Wrocław Division of Electrotechnology and Materials Science \\ M. Skłodowskiej-Curie 55/61, 50-369 Wrocław, Poland \\ ${ }^{b}$ Faculty of Microsystems Electronics and Photonics, Wrocław University of Technology \\ Janiszewskiego 11/17, 50-372 Wrocław, Poland
}

\begin{abstract}
Polyester and polyesterimide compounds for impregnating of electrical motors were modified by incorporating of three kinds of nanofillers: zinc oxide, fumed nanosilica and titanium dioxide so as to improve their properties. Nanosized particles were added at $1 \mathrm{wt} . \%$ of loading and homogeneously dispersed in polyester and polyesterimide matrix. The results on mechanical, electrical and barrier properties of standard and nanofilled compounds were compared. Thermogravimetric/differential thermal analysis showed that thermal stability of nanofilled compounds was significantly higher. Also the electrical and bonding strength of nanofilled impregnating compounds increased and at the same time water absorption decreased. The highest improvement of properties owing to nanofillers was obtained in the case of nanosilica.
\end{abstract}

PACS numbers: 81.07.Pr, 82.35.Np

\section{Introduction}

Polymer nanocomposites, a class of polymers reinforced with low quantities of well-dispersed nanoparticles offer advantages over conventional composites. The research on polymeric nanocomposite dielectrics has been conducted for several years. It has been proved that when the sizes of nanofillers are very small (at least one of their dimensions is under $100 \mathrm{~nm}$ ), the interface regions are so large that they start to interact at very low level of loadings. Nanoparticles have great effect on the properties and morphology of polymeric nanocomposite due to their large specific surface and high surface energy. The interactions between polymer matrix and nanoparticles alter polymer chemistry, i.e. chain mobility and degree of cure and generate new trap centers in the composite which brings about the significant change in electrical properties [1-8]. Where the size of the particle is close to that of the polymer chain length, the particles do not behave like foreign inclusions and space charge densities are small $[6,9,10]$. While microcomposites show significant Maxwell-Wagner interfacial polarisation at low frequencies, nanocomposites show quite different behaviour known as "low-frequency dispersion" or "quasi-DC" behaviour [6, 11-14].

Nanoscale dispersion of fillers in the polymer reinforces their mechanical, thermal and dielectrical prop-

* corresponding author; e-mail: gornicka@iel.wroc.pl erties compared to neat resins $[5,7,8,15-28]$. In the improvement of dielectrical properties both the enhanced scattering of the nanocomposite and mitigation of internal charge may play a role [8].

The purpose of this study was to develop the new nanofilled insulating materials, that would be both resistant to electrical stresses coming from inverters and to exhibit the better mechanical endurance, appropriate for application in high-speed revolution motors. It was assumed that composites modified by incorporating of nanoparticles of nanosilica, titanium dioxide and zinc oxide can meet these requirements.

\section{Experimental}

To carry out this experiment the impregnating polyester and polyesterimide compounds were added with the following nanoparticles: fumed nanosilica (specific surface $380 \mathrm{~m}^{2} / \mathrm{g}$, particle size $7 \mathrm{~nm}$ ), titanium dioxide (specific surface $200 \mathrm{~m}^{2} / \mathrm{g}$, particle size $<25 \mathrm{~nm}$ ), zinc oxide (specific surface $25 \mathrm{~m}^{2} / \mathrm{g}$, particle size $<100 \mathrm{~nm}$ ). Nanosized particles doped with special additives were added at the rate of $1 \mathrm{wt} . \%$ and homogeneously dispersed in a liquid polymer matrix by means of ultrasonic mixer and laboratory high torque disperser. For the proper dispersing of nanoparticles in a liquid, the special method of mixing to a colloidal dispersion was developed. As a result, the new compounds with the long "shelf life" (i.e. six months without sedimentation) have been obtained, which confirms thesis that phenomena that occur in nanocomposites can also be considered 
in the aspect of model system for molecules as a colloid suspension. Below the results on investigation of electrical, mechanical and barrier properties of standard and nanofilled compounds were presented and compared.

\section{Test results}

The compounds dielectrical properties, i.e. electrical strength and resistance to partial discharges were trailed on samples in a form of steel panels coated with a given compound. The electrical strength was tested according to IEC 60243-1 method, using ball to plate type of electrode arrangement as per IEC 60646-2. The results of electrical strength of polyesterimide compounds are presented in Fig. 1. In electrical strength the polyesterimide nanocomposite with nanosilica exhibited more than $40 \%$ improvement upon that without fillers, while in the case of other nanofillers the advantage was not so evident. The other authors $[8,3]$ found that the electrical strength behaviour due to nanofillers is not so univocal and electrical strength can increase but also decrease. The weakness can be caused by nanoparticles agglomeration or interphase interactions $[6,7,12,15,24]$. The improvements of electrical strength may be due to well-known scattering mechanism occurring in filled composites [3]. This effect, which relies on the extending the routes of the charge carriers, is also known as "barrier effect" or "labyrinths effect".

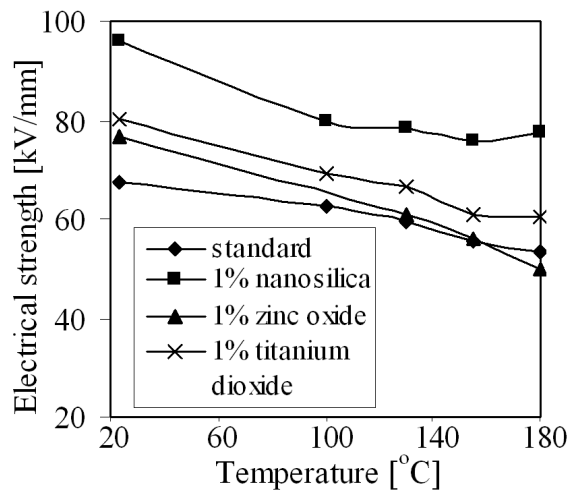

Fig. 1. Electrical strength vs. temperature of the standard and nanofilled polyesterimide compounds.

The compounds resistance to partial discharges (PD) was evaluated by measurement of their lifetimes under $\mathrm{PD}$ activity by applying the repetitive bipolar square impulse voltage. The severity of test $(1100 \mathrm{~V} / 20 \mathrm{kHz})$ was such as to exceed the partial discharge inception voltage (PDIV) of the compositions. The PD failure times were recorded and plotted in a Weibull distribution curve, in which the alpha value (63\% probability) was taken as an average lifetime of the sample. The example of compound with $1 \% \mathrm{ZnO}$ is shown in Fig. 2.

The lifetime of polyesterimide impregnating compound nanofilled with nanosilica appeared to be more than 20 times longer than that of the standard compound. As

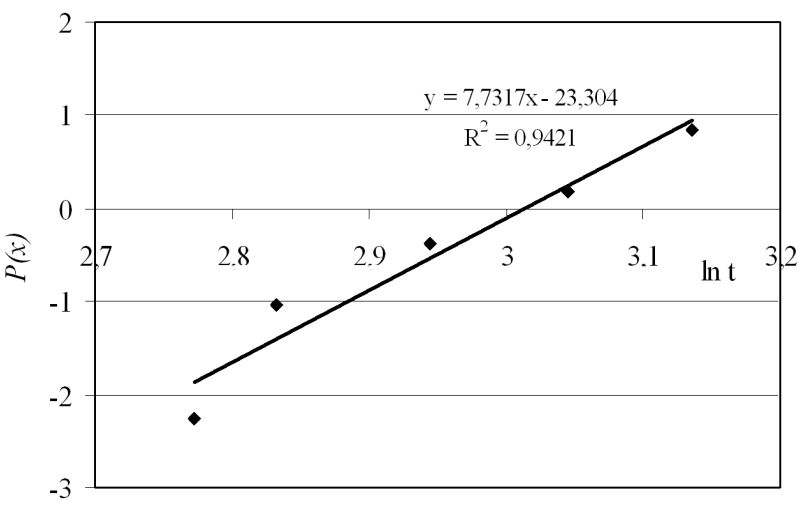

Fig. 2. Weibull probability function $P(x)$ vs. lifetime of compound with $1 \% \mathrm{ZnO}$.

a result of incorporation of $\mathrm{TiO}_{2}$ and $\mathrm{ZnO}$ nanoparticles the composite lifetimes was elongated by 6 and 4 times, respectively (Fig. 3). The best results were obtained for compounds modified with nanosilica, whose grain sizes were the smallest. The fact that adding of nanofiller may lead to meaningful elongation of the polymer lifetime under partial discharges has been reported in literature $[2,6,7,11,12,24]$ and is also ascribed to the above mentioned barrier effect which restricts partial discharges penetration (shielding effect) and diminishes the erosion.

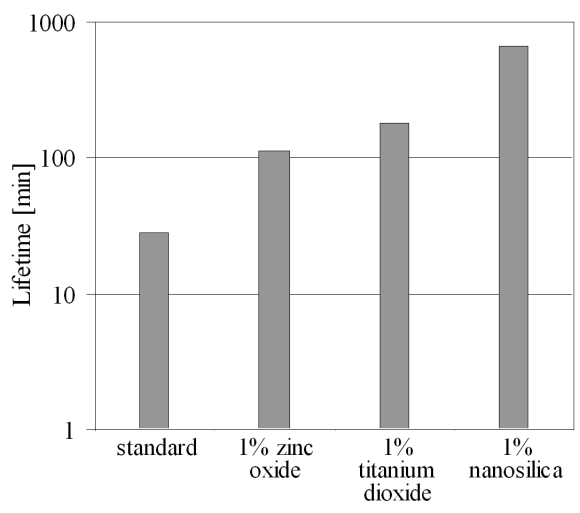

Fig. 3. Comparison of lifetimes of standard and nanofilled polyesterimide compounds under pulse voltage $1.1 \mathrm{kV} / 20 \mathrm{kHz}$.

The water absorption was tested according to ISO 62 . In nanocomposites after $120 \mathrm{~h}$ of immersing them in water it decreased (Fig. 4), as a result of the nanoparticles barrier effect on water permeaiting.

Figure 5 presents the results on bond strength testing as per IEC 61033 of both standard and nanofilled polyester compounds. The bond strength of all the nanocomposites increased and the enhancement was in the range from $60 \%$ in the case of zinc oxide nanofiller to $80 \%$ in the case of nanosilica. Figure 6 shows that the bond strength of the nanofilled polyesterimide compounds at elevated $\left(180^{\circ} \mathrm{C}\right)$ temperature also improves. 


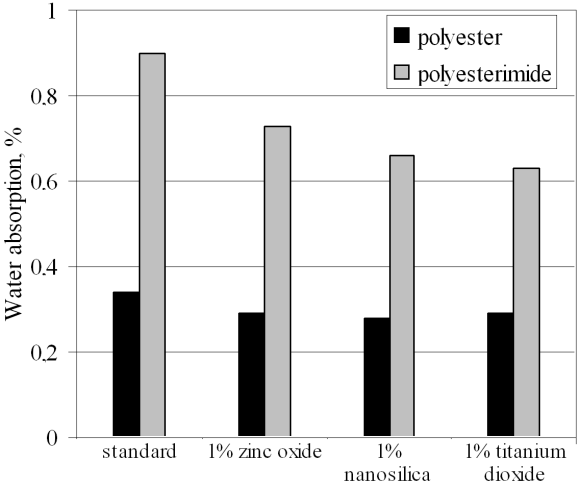

Fig. 4. The water absorption of standard and nanofilled polyester and polyesterimide compounds after $120 \mathrm{~h}$ immersing in water.

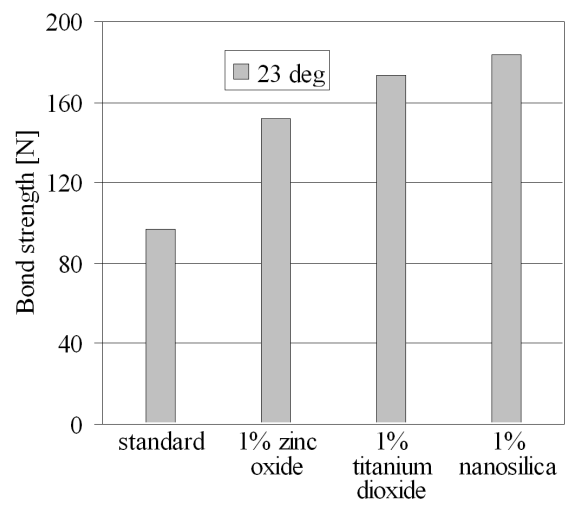

Fig. 5. Bond strength of the standard and nanofilled polyester compounds at $20^{\circ} \mathrm{C}$.

This enhancement may be attributed to the generation of the additional cross-couplings at polymer-nanofiller interfaces.

To estimate the influence of nanofillers on the thermal stability of the polyester and polyesterimide impregnating compounds, the thermoanalytical testing in the temperature range from 25 to $900^{\circ} \mathrm{C}$ was performed using thermogravimetric/differential thermal analysis (TGA/DTA) method. It was established that, irrespectively of the type of nanofiller, the nanofilled polyester compounds improved their thermal stability at the same rate. The TGA/DTA data for polyester and polyesterimide resins with nanosilica are presented in Fig. 7. It can be noticed that decomposition temperatures of both nanofilled polymers increase up to $360^{\circ} \mathrm{C}$, even though the initial values had been quite different. It may be because the polymer with poorer initial properties (polyester) was more ready to generate the additional chemical or physical bonding centers.

\section{Conclusion}

Polyester and polyesterimide compounds for impregnating of electrical motors modified with nanoparticles of

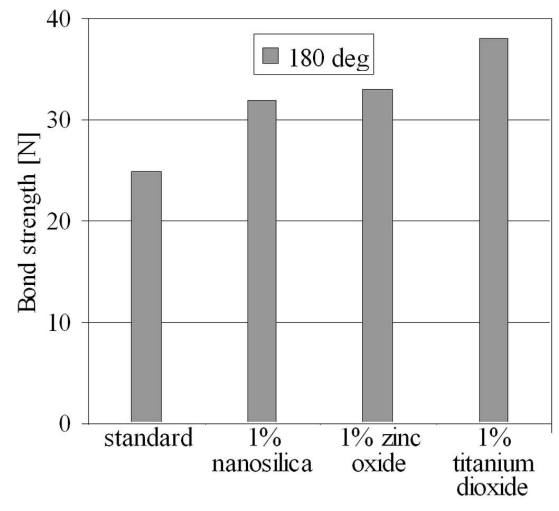

Fig. 6. Bond strength of the standard and nanofilled polyesterimide compounds at $180^{\circ} \mathrm{C}$.

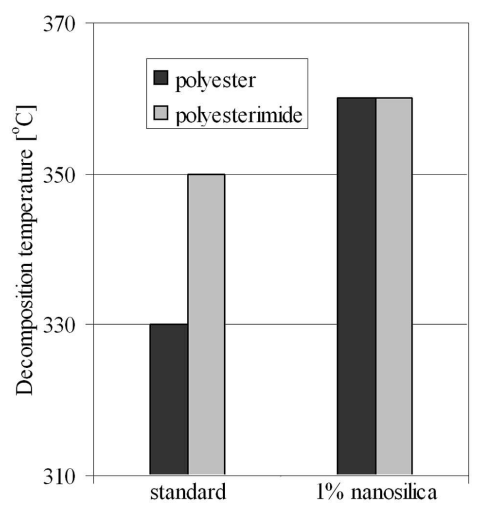

Fig. 7. The decomposition temperatures of standard and filled with nanosilica polyester and polyesterimide compounds.

$\mathrm{SiO}_{2}, \mathrm{TiO}_{2}$ and $\mathrm{ZnO}$, when compared to standard compounds, show improved dielectrical properties and better water resistance, which may be attributed to scattering mechanism, caused by introduction of a second nanosized phase. The obtained nanofilled compounds also exhibit the better mechanical and thermal properties, probably due to generating of the additional cross-couplings in the interfaces. The best properties have been obtained for compounds added with nanosilica, which may result from the fact that nanosilica was characterised by the smallest sizes of nanoparticles among nanofillers used in this experiment.

\section{Acknowledgments}

This work was financed from the sources for science development in the years 2007-2010, as a development project No. 0490/R/T02/2007/03.

\section{References}

[1] T. Tanaka, IEEE Trans. Diel. Electr. Insul. 12, 914 (2005). 
[2] T. Tanaka, M. Kozako, N. Fuse, Y. Ohki, IEEE Trans. Diel. Electr. Insul. 12, 914 (2005).

[3] M. Roy, J.K. Nelson, R.K. MacCrone, L.S. Schadler, C.W. Reed, R. Keefe, W. Zenger, Trans. IEEE DEI-12, 629 (2005).

[4] A.J. Bur, S.C. Roth, M. McBrearty, http:// polymer.nist.gov/uploads/bur0203.pdf .

[5] J.K. Nelson, L.A. Track, R.K. Macron, C.W. Reed, in: Proc. Conf. on Electrical Insulation and Dielectric Phenomena, Boulder (CO) 2004, IEEE 2004, p. 314.

[6] J.K. Nelson, J.C. Fothergill, L.A. Dissado, W. Peasgood, in: Electrical Insulation and Dielectric Phenomena, 2002 Annual Report Conf., IEEE 2002, p. 295.

[7] H. Li, G. Liu, B. Liu, W. Chen, S. Chen, Mater. Lett. 61, 1507 (2007).

[8] J.K. Nelson, Y. Hu, Solid Diel. 2, 832 (2004).

[9] F.M. Erguney, H. Lin, W.L. Mattice, Polymer 47, 3689 (2006).

[10] Y. Yin, J. Chen, J. Yang, D. Xiao, D. Tu, R. Yin, H. Qian, in Proc. 7th Int. Conf. on Properties and Applications of Dielectric Materials, Nagoya 2003, IEEE 2003, p. 913.

[11] J.K. Nelson, J.C. Fothergill, 2004, https:// lra.le.ac.uk/bitstream/2381/4056/1/ paper20.pdf

[12] C. Zou, J.C. Fothergill, M. Fu, J.K. Nelson, 2006, https://lra.le.ac.uk/bitstream/2381/4068/1/ paper11.pdf .

[13] J.C. Fothergill, 2007, https://lra.le.ac.uk/ bitstream/2381/4001/1/paper05.pdf .

[14] Y. Hu, R.C. Smith, J.K. Nelson, L.S. Schadler, in: Proc. Conf. Electrical Insulation and Dielectric Phenomena, 2006 IEEE Conf., IEEE 2006, p. 31.
[15] Y. Yin, X. Dong, Z. Li, X. Li, in: Proc. 2007 Int. Conf. on Solid Dielectrics, Winchester (UK) 2007 IEEE 2007, p. 372

[16] J.I. Hong, P. Winberg, L.S. Schadler, R.W. Siegel, Mater. Lett. 59, 473 (2005).

[17] Ch. Ho Dan, M. Ho Lee, Y. Doo Kim, B. Hun Min, J. Ho Kim, Polymer 47, 6718 (2006).

[18] A.N. Guz, J.J. Rushchitsky, I.A. Guz, Int. Appl. Mech. 43, 247 (2007).

[19] Ch. Ding, D. Jia, H. He, B. Guo, H. Hong, Polymer Testing 24, 94 (2005).

[20] J. Zheng, R. Ozisik, R.W. Siegel, Polymer 46, 10873 (2005).

[21] U. Kim Jauep, B. O'Shaughnessy, Phys. Rev. Lett. 89, 23 (2002).

[22] Ch. Hub, S.H. Harton, M.A. Hunt, R. Fink, H. Ade, published online in Wiley InterScience, www.interscience.wiley.com , p. 2270.

[23] Y.H. Lai, M.C. Kuo, J.C. Huang, M. Chen, Mater. Sci. Eng. A 458, 158 (2007).

[24] T. Imai, F. Sawa, T. Yoshimitsu, T. Ozaki, T. Shimizu, as Ref. [5], p. 402.

[25] D. Fragiadakis, P. Pissis, L. Bokobza, Polymer 46, 6001 (2005)

[26] J. Zhang, D.D. Jiang, D. Wang, Ch.A. Wilkie, Polym. Degrad. Stability 91, 2665 (2006).

[27] P. Meneghetti, S. Qutubuddin, Thermochim. Acta 442, 74 (2006).

[28] S. Yu, J. Zhao, G. Chen, J.K. Juay, M.S. Yong, J. Mater. Proc. Technol. 192-193, 410 (2007). 